\title{
Structured Training for Fetal Diagnostic Skills in a Maternal-Fetal Medicine Fellowship
}

\author{
Kathleen M. Antony, MD, MSCI ${ }^{1}$ Nauman Khurshid, $\mathrm{MD}^{1,2}$ Barbara Trampe, BA, RN, RDMS 3 \\ Vivek K. Gupta, MD ${ }^{1}$ J. Igor Iruretagoyena, MD $^{1}$ Katharina S. Stewart, MD ${ }^{1}$ Dinesh Shah, MD ${ }^{1}$
}

\footnotetext{
${ }^{1}$ Division of Maternal-Fetal Medicine, Department of Obstetrics and Gynecology, University of Wisconsin School of Medicine and Public Health, Madison, Wisconsin

2 Division of Maternal-Fetal Medicine, Department of Obstetrics and Gynecology, ProMedica Toledo Hospital, University of Toledo, Toledo, Toledo, Ohio

3 Meriter Center for Perinatal Care, Meriter-UnityPoint Health,

Madison, Wisconsin
}

\begin{abstract}
Address for correspondence Kathleen M. Antony, MD, MSCl, Division of Maternal-Fetal Medicine, Department of Obstetrics and Gynecology, University of Wisconsin School of Medicine and Public Health, 1010 Mound Street, 4th Floor, Madison, WI 53715 (e-mail: kantony@wisc.edu).
\end{abstract}

Am J Perinatol Rep 2018;8:e251-e260.

\begin{abstract}
Keywords

- ultrasound training

- fetal diagnosis

- maternal-fetal medicine fellowship

- ultrasound curriculum

- medical education

- obstetric ultrasound

Objective The American Institute of Ultrasound in Medicine has described what constitutes a detailed fetal anatomic examination but what comprises an appropriate physician training program has not been described. The purpose of this paper is to describe a highly-structured program developed by our center to train maternal-fetal medicine fellows in a systematic approach to fetal diagnostic imaging.

Study Design We describe this approach in three phases. Phase I: Development of Skills as a Perinatal Sonographer, Phase II: Mentored Evolution to a Perinatal Sonologist and Phase III: Supervised Independent Practice as Consultant-in-training.

Results This curriculum was implemented in 2006. Of the eight maternal-fetal medicine fellows who completed this program, $100 \%$ were capable of following this curriculum and $100 \%$ felt comfortable performing and interpreting detailed sonograms including sonograms with significant and uncommon anomalies. Qualitative feedback was also positive. Finally, this structured approach resulted in an increase in the average total number of sonograms interpreted.

Conclusion Our curriculum, by following the explicit guidelines and expectations set out by the American Institute of Ultrasound in Medicine and the American Board of Obstetrics and Gynecology for practicing maternal-fetal medicine fellowship graduates, provides an opportunity to explore national standardization for this component of training.
\end{abstract}

Prenatal diagnosis is an essential component of the maternal-fetal medicine (MFM) subspecialty. Arriving at proficiency in this field requires the MFM physician to have sound technical skills in obtaining images that establish or confirm a diagnosis, solid skills in seeking and finding associated anomalies via a systematic and thorough diagnostic approach, and a command of the evidence-based management strategies for conditions that are encountered.
To ensure that our fellows achieve competence in prenatal diagnosis, we established a structured and integrated process to address training in these areas which we describe here in replicate detail.

The American Institute of Ultrasound in Medicine (AIUM) and the Society of Maternal-Fetal Medicine have issued a joint statement that describes what constitutes a basic (76805) and detailed (76811) fetal anatomic examination. ${ }^{1}$ received

November 14, 2017 accepted after revision

September 5, 2018
DOI https://doi.org/

10.1055/s-0038-1675344. ISSN 2157-6998.
Copyright $\odot 2018$ by Thieme Medical Publishers, Inc., 333 Seventh Avenue, New York, NY 10001, USA. Tel: +1(212) 584-4662.
License terms

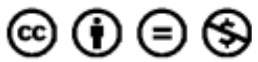


This statement also asserts that physicians performing or interpreting the detailed fetal anatomic ultrasound must be appropriately trained obstetricians, maternal-fetal medicine specialists, or radiologists with special expertise in fetal imaging, or they must maintain a log demonstrating that they have participated in the scanning and interpretation of at least 100 detailed fetal anatomic scans including at least 25 fetal cases with major morphologic abnormalities. ${ }^{1}$ However, what constitutes appropriate physician training has not been recently described. ${ }^{2}$ The MFM specialty training is broad and has several components which have competing interests on the time commitment of the MEM fellows. It therefore is essential to have a formal training process in fetal diagnosis to achieve acquisition of the skills efficiently. Residency training in obstetrics and gynecology is not designed to provide ultrasound training at an advanced level and what ultrasound training does occur is not standardized across institutions; in a survey of 4,666 obstetrics and gynecology residents, only $16.3 \%$ indicated that training in the performance and interpretation of fetal ultrasound examinations were mandatory. ${ }^{3}$ Therefore, it is fair to assume that newly-arriving MFM trainees may have limited and variable experience with ultrasound.

The purpose of this paper is to describe a highly-structured program to train MFM fellows in a methodological approach to fetal diagnostic imaging. Here, we present this model in reproducible detail.

\section{Materials and Methods}

This structured, one-on-one, and hands-on curriculum was started in the fall of 2006 and was analyzed in the fall of 2016. To design this curriculum, we applied the backward design model of Wiggins and McTighe that is a process by which outcomes and assessment drive curriculum design to develop our prenatal diagnostic training program. ${ }^{4}$ The agreed upon outcome, in this case, is the successful performance and interpretation of a detailed fetal anatomic ultrasound examination. Development of such a training process to meet specific desired outcomes is, in effect, one of the goals of the Accreditation Council for Graduate Medical Education (ACGME) Milestones Project. ${ }^{5}$ By defining the endpoint or competencies that a trainee will demonstrate at the end of their training, the ACGME was the driver of curriculum development to meet the milestones for clinical training. ${ }^{5}$ Calhoun and Hume ${ }^{2}$ have presented a multistage obstetrics curriculum for AIUM-accredited ultrasound diagnosis centers; here we describe a process for development of subject and skill acquisition and attainment of mastery in a clinical environment. While an understanding of the fundamentals of genetics and genetic counseling related to genetic screening and testing options is also a critical component of prenatal diagnostic training; our month-long genetics curriculum is not described here.

All learning occurs within the UnityPoint-Meriter Center for Perinatal Care which is a collaborative center between UW Health and UnityPoint Health-Meriter and is the clinical home of the division of MFM. Institutional review board oversight was not required for this project because information was gathered as part of usual fellow assessment and feedback sessions. This unit has eight ultrasound machines with seven dedicated sonography examination rooms and a portable unit utilized for the antepartum fetal surveillance schedule in the adjacent clinic. Our unit performs 15,500 ultrasound examinations annually, comprised of 2,200 detailed fetal anatomic examinations, 1,100 basic fetal anatomic examinations, 1,600 first trimester screening examinations, 600 fetal echocardiograms, and 10,000 other examinations. Our average number of examinations is 45 daily. Here we use the terms "basic" and "detailed" to refer to current procedural terminology (CPT) codes 76805 and 76811, respectively. ${ }^{1}$

Our unit was redesigned in the fall of 2011 with input from outside consultants and all relevant stakeholders using the Lean Six Sigma process which accounted for a registered diagnostic medical sonographer (RDMS) educator training adult learners, specifically MFM medicine fellows. ${ }^{6}$ Furthermore, our clinical schedule templates for the fetal diagnosis unit were redesigned to improve unit efficiency while allowing protected time for the educator to provide fellow handson teaching.

This program is directly supervised by a senior RDMS educator who is committed to education, in addition to the fellowship director, and the MFM faculty members. The broad assignment for the sonographer educator is to develop and implement training programs for our residents and fellows and to support learners from other departments as well. In our training model, it is essential for the academic department to protect the RDMS educator at 50\% full time equivalent for educational activities. While many academic units describe having a senior sonographer educator as an asset, unless this person has dedicated teaching time supported by the academic budget, the educator's role is not effectively implemented. Additionally, while we describe that the fellow performs hands-on scanning with the RDMS educator after the completion of an ultrasound examination, a patient's time in the ultrasound unit is not substantially increased because this scanning occurs while the sonographer who performed the examination is presenting the case to the interpreting physician.

When selecting a senior RDMS educator, it is helpful to select an individual with graduate level training experience for this role, although this is by no means required. The most essential characteristics of the senior RDMS educator are that he or she be motivated to teach, have a level of expertise in advanced diagnostics (ideally 5 or more years in a unit that performs targeted exams), a keen awareness of specific diagnostic and exam criteria for each exam type, and dedicated time devoted to developing curriculum and the implementation of it. As an example, our RDMS educator has a B.A. in healthcare management in addition to an RN and RDMS, and 30 years of experience in obstetric ultrasound, 22 of which have included teaching. Here, our RDMS educator assumed roles in both curriculum design and implementation. The ultimate hypothesis was that hands-on, one-on-one attention would accelerate a learner's efficiency at understanding the technical aspects of scanning itself and 
optimizing the use of settings and knobology, and therefore improve the sonographic skills of our fellows from a variable baseline to technical proficiency at obtaining images within 8 weeks.

Competency is a complex topic that depends upon a physician's planned scope of practice but globally requires a combination of knowledge and technical skills. ${ }^{3}$ The ACGME has designed five levels of proficiency (milestones) that define targets for graduation. These are not designed to represent graduation requirements, per se but to provide a general framework for competency. ${ }^{5}$ Using the competencies, we defined a skill set that our fellow trainees should master by following a standardized, scaffolded curriculum to sequentially obtain and master the requisite skills to complete and interpret prenatal diagnostic sonograms. Training also includes guidance in appropriate use of consultants and diagnostic testing and in genetic counseling. We describe this approach in three phases which allows for the progressive acquisition of skills. The overarching goal of phase $I$ is to develop advanced imaging skills similar to the skill level of a perinatal sonographer. The goals of phases II and III are to expand the fellow's skills at interpreting images to formulate a diagnosis and to develop into an academic physician sonologist with skills in communication, genetic counseling, patient education, and evidence-based practice in co-ordination of care. Our program hopes to embody a specific practical approach in the tradition of Malcolm Knowles, based on his conception of self-directed and autonomous learners and teachers as facilitators of learning. ${ }^{7}$

This curriculum spans the 3 years of fellowship training and is divided into three separate 8-week blocks. Three months of ultrasound training are required by the American Board of Obstetrics and Gynecology (ABOG) to fulfill the training requirements of a MFM fellowship. ${ }^{8}$ The additional 3 months in this curriculum are garnered from elective time as per the discretion of the program director as allowed by ABOG. ${ }^{8}$ The program's three phases are outlined below and summarized in - Table $\mathbf{1}$.

\section{Phase I}

The goal of this first 8-week rotation is to teach the fellow how to perform a fetal ultrasound examination independently. During this phase, the fellow is exempt from clinical duties except for his or her allotted 4 hours of high-risk obstetric continuity clinic as per ABOG guidelines. ${ }^{8}$ The fellow, therefore spends the majority of his or her time in the ultrasound unit with the RDMS educator. Since both the RDMS educator and fellow have a full 8-hour work day to spend on this training, the goals are achievable during an 8week rotation despite the steep learning curve.

Week 1 starts with a review of the goals of the rotation and methods to achieve the stated goals. This is followed by an orientation to the ultrasound unit, and an introduction to personnel including the clerks, medical assistants, nurses, and schedulers, and familiarization with the patient flow of the unit. All fellows are also given a binder with a description of the unit, a list of recommended textbook resources, and required articles to read including the International
Society of Ultrasound in Obstetrics and Gynecology (ISUOG) basic ultrasound training guidelines, and the AIUM practice guidelines. ${ }^{9,10}$ The contents of this binder are listed in - Supplemental Table $\mathbf{S 1}$ (available online only).

Since all fellows are assumed to have no formal ultrasound training, regardless of their background, the teaching starts with an introduction to ultrasound principles, theories, and practices. This includes discussion of the controls and acoustical output, the ALARA (as low as reasonably achievable) principle, and instruction on probe orientation. The fellows are then evaluated by the senior RDMS educator for their current technical skills level which is assessed via hands-on scanning. This serves as a foundation to build upon, correcting any previous misconceptions, or acquired habits. Selected patients are verbally consented for ultrasound training purposes, and the RDMS educator demonstrates how a basic fetal examination is performed. This teaching includes patient positioning, operator hand positioning, and developing orientation to fetal position in the context of maternal anatomic landmarks, three-dimensional (3D) orientation to the fetal position, and how to refine image quality by using ultrasound software. Understanding and implementing functions of various knobs is emphasized as the fellow starts to perform scanning. The fellow is only allowed to proceed to the next level of training after the RDMS educator determines that an acceptable level of skill has been achieved for that current task. This initial process is crucial to build a practical knowledge base of ultrasound physics and software and to provide a sound foundation in physical orientation for fetal examination. During this week, time is also allocated to the observation of basic or detailed anatomic examinations.

In the subsequent weeks, fellows are introduced to AIUM guidelines and documents that outline the components of a basic and detailed fetal anatomic examination and the correct approach to obtain views of the fetal anatomy. ${ }^{9}$ We have developed a standardized and organized hands-on training approach to develop the crucial hand-eye coordination necessary to scan effectively. The fellow begins by obtaining real-time "sagittal spine images," following the curve of the entire fetal spine with guidance from the RDMS educator. The RDMS educator uses this exercise to teach the fellow the transducer movements shown in - Fig. 1. We refer to these movements as the "windshield wiper" and "central pivot" maneuvers. This is repeated multiple times until the fellow acquires this skill. These scanning techniques are the foundation of all other movements. Additional standard ultrasound probe maneuvers are then added and extensively practiced to obtain classic targeted fetal sectional images. Small dolls are used to orient the fellow to the 3D aspect of fetal position, lie, and situs, and for trouble-shooting with difficulties in image acquisition. Once hand-eye coordination instructions and exercises are completed, the fellow is introduced to the basics of fetal biometry and anatomy.

By the end of first month, fellows are expected to perform and obtain basic anatomic images with the exception of the fetal heart. The ability to obtain all required basic anatomic images (except the fetal heart) is confirmed by completing the middle column of the checklist shown in -Supplemental Figure S1 
Table 1 Phase I: 8 wk by the end of this phase, the fellow show they have the basic skills of a perinatal sonographer

\begin{tabular}{|c|c|}
\hline Goals & Objectives \\
\hline \multicolumn{2}{|l|}{ Wk 1} \\
\hline $\begin{array}{l}\text { Introduction to the } \\
\text { ultrasound unit }\end{array}$ & $\begin{array}{l}\text { - Discuss goals and objectives of phase I } \\
\text { - Observe the work flow of the unit } \\
\text { - Orientation to the materials binder (Supplemental Table S1) } \\
\text { - Review ALARA via didactic lectures } \\
\text { - Acquire basic ultrasound physics knowledge, knobology, and how to apply different system } \\
\text { - } \text { Settings via didactic lectures } \\
\text { lanserve basic and detailed fetal anatomic examinations emphasizing recognition of normal } \\
\text { - Reading assignments }\end{array}$ \\
\hline \multicolumn{2}{|l|}{ Wk 2} \\
\hline $\begin{array}{l}\text { Assessment of current } \\
\text { ultrasound skills, including } \\
\text { understanding of terminol- } \\
\text { ogy and development of } \\
\text { eye/hand co-ordination }\end{array}$ & $\begin{array}{l}\text { - Review AIUM ultrasound guidelines } \\
\text { - Didactic lectures on the basic and detailed anatomic examination } \\
\text { - Obtain sagittal spine images as a method to develop eye/hand/brain co-ordination } \\
\text { (windshield wiper and central pivot transducer movements }{ }^{\mathrm{a}} \text { - - Fig. 1) } \\
\text { - Document fetal number/viability/lie/presentation } \\
\text { - Describe fetal situs using doll models } \\
\text { - Demonstrate understanding of ultrasound software and knobology (ultrasound machine } \\
\text { and computer) }\end{array}$ \\
\hline \multicolumn{2}{|l|}{ Wk 3} \\
\hline $\begin{array}{l}\text { Completion of basic } \\
\text { biometry and assessment of } \\
\text { fetal well-being. }\end{array}$ & $\begin{array}{l}\text { - Obtain accurate measurements of femur, humerus, abdominal circumference, biparietal } \\
\text { diameter and head circumference } \\
\text { - Didactic lecture on extremes of amniotic fluid } \\
\text { - Assess amniotic fluid volume/perform biophysical profile }\end{array}$ \\
\hline \multicolumn{2}{|l|}{ Wk 4} \\
\hline $\begin{array}{l}\text { Independent assessment of } \\
\text { fetal anatomy by region }\end{array}$ & $\begin{array}{l}\text { - Under supervision of sonographer educator, reproduce and document basic fetal anatomic } \\
\text { examination (AIUM guidelines, code 76805), excluding heart } \\
\text { - Didactic lectures on cervical length measurements in accordance with the CLEAR guidelines } \\
\text { - Document appropriate cervical length images and assess placentation (CLEAR guidelines) }\end{array}$ \\
\hline \multicolumn{2}{|l|}{ Wk 5} \\
\hline $\begin{array}{l}\text { Completion of fetal anat- } \\
\text { omy, including basic cardiac } \\
\text { imaging }\end{array}$ & $\begin{array}{l}\text { - Acquire heart views including 4-chamber, outflow tracts, 3-vessel view, 3-vessel tracheal } \\
\text { view (Heart model available for understanding) } \\
\text { - Independently complete a basic fetal anatomic examination }\end{array}$ \\
\hline \multicolumn{2}{|l|}{ Wk 6} \\
\hline $\begin{array}{l}\text { Independent completion of } \\
\text { detailed anatomic assess- } \\
\text { ment and introduction to } \\
\text { first-trimester screening and } \\
\text { invasive procedures }\end{array}$ & $\begin{array}{l}\text { - Independently document detailed anatomic images (AIUM guidelines, code 76811) } \\
\text { - Perform basic multiple gestations scan } \\
\text { - Didactic lecture on first trimester screening } \\
\text { - NTQR online didactic to prepare for collection of images for NTQR certification } \\
\text { - Acquire images for first trimester screens (NTQR certification at annual SMFM meeting) } \\
\text { - Perform amniocentesis on simulation model }\end{array}$ \\
\hline \multicolumn{2}{|l|}{ Wk 7} \\
\hline $\begin{array}{l}\text { Introduction to Doppler's } \\
\text { ultrasound and genetic } \\
\text { counseling, with focus on } \\
\text { abnormal exam findings }\end{array}$ & $\begin{array}{l}\text { - Demonstrate Doppler's imaging of umbilical and middle cerebral artery } \\
\text { - Review and discuss abnormal fetal evaluations from previously collected database cases } \\
\text { - Participate in discussion during genetic counseling of normal and abnormal cases } \\
\text { - Didactic lectures on aneuploidies } \\
\text { - Didactic lectures on skeletal dysplasias }\end{array}$ \\
\hline \multicolumn{2}{|l|}{ Wk 8} \\
\hline $\begin{array}{l}\text { Demonstration of basic } \\
\text { competencies as a perinatal } \\
\text { sonographer }\end{array}$ & $\begin{array}{l}\text { - Independently complete and document basic and detailed fetal anatomic examinations } \\
\text { - Demonstrate proficiency in multiple gestation evaluation, with emphasis on chorionicity } \\
\text { - Didactic lectures on multifetal gestation } \\
\text { - Didactic lecture on placenta accreta } \\
\text { - Complete Doppler's assessments }\end{array}$ \\
\hline
\end{tabular}

Abbreviations: AIUM, American Institute of Ultrasound in Medicine; ALARA, as low as reasonably achievable; CLEAR, cervical length education and review; NTQR, nuchal translucency quality review; RDMS, registered diagnostic medical sonographer; SMFM, society for maternal-fetal medicine. ${ }^{a}$ Our senior RDMS educator has devised innovative ways to teach complicated hand movements and given them names the fellow is likely to remember. These are examples of the names. 


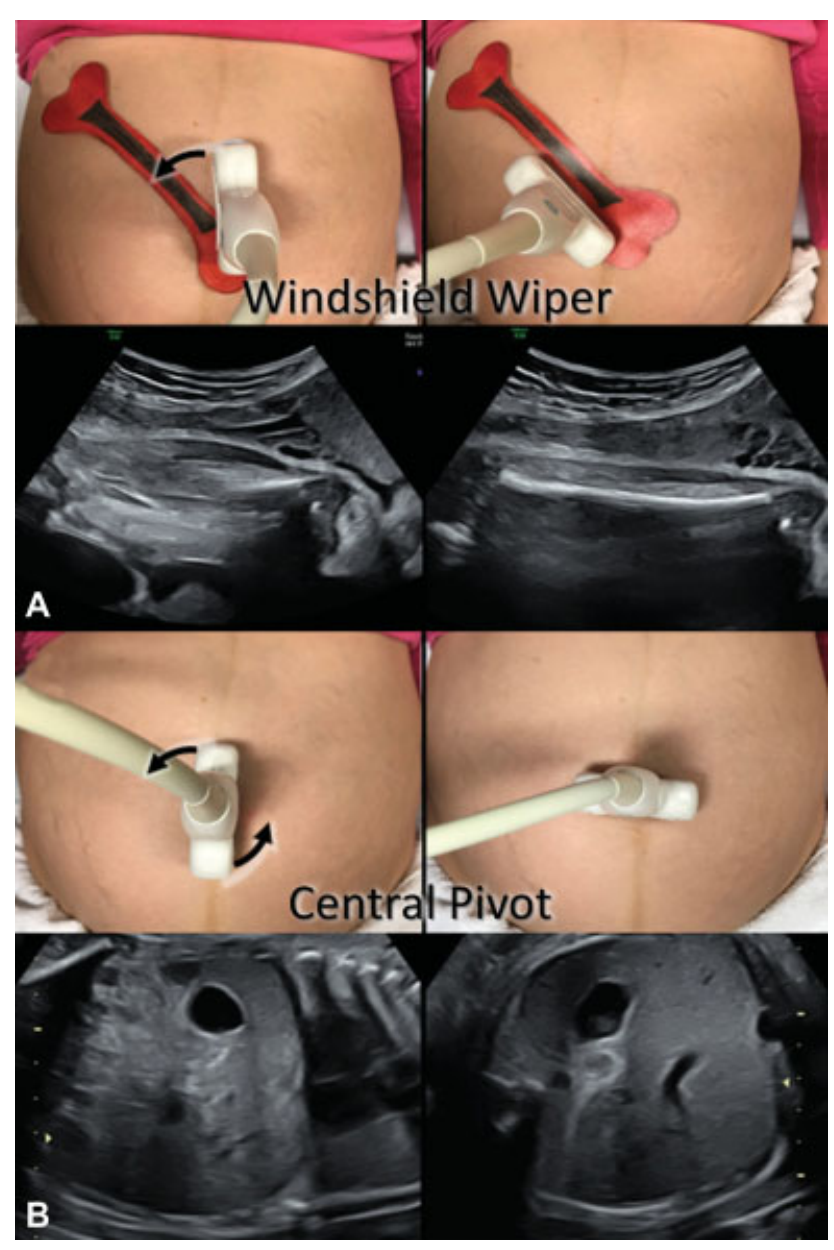

Fig. 1 The "windshield wiper" and "central pivot" transducer movements. (A) It shows the onscreen and onabdomen correlation wherein a long bone is identified near an epiphysis in a transverse plane and the transducer is rotated along a radial pivot, similar to a windshield wiper, to elongate the bone to a longitudinal plane. (B) It shows the onscreen and onabdomen correlation wherein the transducer is rotated 90 degrees along a "central pivot." Here, the maternal umbilicus functions as the central pivot point.

(available online only). Since the senior RDMS educator is present in the room while the fellow scans, immediate feedback is provided for guidance and reflection. Week 4 also includes cervical length assessment following the guidelines of the Cervical Length Education and Review (CLEAR) education courses. ${ }^{11}$ Basic fetal heart views are taught during the subsequent week.

The last 4 weeks of phase I are structured to progress with guidance in scanning techniques and in an efficient approach to the acquisition of advanced fetal anatomic images. It also allows for completion of any skills not completed in the first 4 weeks.

This advanced skill development starts with the acquisition of fetal heart images in various planes and observation of advanced fetal heart imaging with a Pediatric Cardiologist in week 5, first-trimester screening ultrasound lectures and images acquisition in week 6 , completion of a detailed fetal anatomic examination during week 6 , and the introduction to Doppler ultrasound in week 7, all under the direct super- vision of RDMS educator. The emphasis is for the fellow to learn the correct approach to fetal examination the first time and to be able to reproduce images consistently with directly-supervised repetitive experiences. In addition to the Doppler assessment, the last 2 weeks of phase I is devoted to training the fellow in specialized cases, such as multiple gestations, genetic counseling, and a review of didactics and cases with fetal anatomic abnormalities and markers from our own imaging collection. Although fellows do not perform amniocentesis during the first phase, they practice the essential technical skills by using an ultrasound simulation model developed in our own center (data published in abstract form). ${ }^{12}$ At the end of phase I, after adequate competency is demonstrated, the fellow may advance to phase II. At this point, the RDMS educator has first-hand knowledge of the individual fellow's status, and continued guidance and targeted skill development is provided during the subsequent phases of training. Postrotation evaluations are also completed by both the educator and learner.

Fellows meet the criteria for advancement once they are able to efficiently obtain technically satisfactory images to complete a detailed fetal anatomic examination. During phase I, the emphasis remains on image acquisition, thus if fellows exhaust the curriculum for week 8 of phase I early, they are encouraged to further master advanced cardiac and neurologic views rather than progress to interpretation.

\section{Phase II}

The goal of phase II is to develop perinatal sonologist skills which include acquiring technically adequate images, interpreting them, and generating ultrasound reports. The fellow is no longer paired with the RDMS educator after completion of phase I, and now learning follows an apprenticeship model of teaching from the MFM faculty member assigned as the attending physician to the fetal diagnosis unit. In the next 8 weeks, the fellow undergoes intensified training by reviewing images acquired by perinatal sonographers and interpreting normal and abnormal scans under direct physician supervision. The perinatal sonographer performing the scan initially presents the case to the fellow who reviews the images with the sonographer. After a preliminary discussion, the fellow then reviews the case with the attending physician. After completion of the diagnostic review, the sonographer moves on to the next patient. As per unit protocol, the fellow then proceeds to direct scanning of the patient to confirm normal or abnormal findings, or to attempt completion of the anatomic survey. During the scanning period, the fellow discusses the findings with the patient as previously role-modeled by the attending physician. Care is taken to allow the fellow to gradually move from reviewing normal cases to being assigned to abnormal cases. Follow-up appointments, as per unit guidelines are discussed by the fellow. The fellow is expected to complete the report before attending to the next patient. This step is crucial to learning the use of reporting software and provides the fellow real-life experience to acclimate to the patient volume and unit flow. Both the images and the report are reviewed by the attending physician and direct feedback is provided contemporaneously on a case-by-case basis. 
Occasionally, when there is a high patient volume, the attending physician takes an active role assuming direct responsibility for some cases to maintain patient flow in the unit.

Abnormal cases require additional attention and a multidisciplinary approach. All abnormal cases that are identified by the sonographer are presented to the fellow and the attending physician at the same time. Once findings are confirmed, a genetic counselor and the perinatal care coordinator (a clinical nurse specialist) are informed. The MFM attending physician, the fellow, and the genetic counselor see the patient together. Confirmation examination for specific findings is performed by brief scanning, initially by the attending physician and gradually this responsibility is shifted to the fellow. After the patient has been provided with an explanation of findings and a brief overview of differential diagnosis, the genetic counselor assumes direct responsibility for the patient and provides targeted counseling. Through this role-modeling process, fellows learn how to communicate findings with patients and how to co-ordinate care with referring practitioners and the fetal interventionists or postnatal specialists to whom patients are referred. If indicated, invasive procedures are scheduled and performed by the fellow under the direct supervision of the attending physician. When indicated, an MFM consultation visit is performed or scheduled for a future time.
During this phase, the fellow also participates in specialized ultrasound examinations performed in our unit, such as fetal echocardiography and neurosonography. ${ }^{13}$ On our unit, fetal echocardiograms are performed by obstetric sonographers under the supervision of pediatric cardiologists, both of whom contribute to the education of the MFM fellow. Neurosonography is performed by a MFM specialist with specialized training in the performance and interpretation of the fetal neurosonogram (JII).

By the end of phase II, fellows are ready to review images and interpret them, perform and supplement examinations performed by the sonographer, present results of the sonogram to the patient or couple, present and describe abnormal findings to referring physicians, integrate care with genetic counselor and perinatal coordinator, and provide physician leadership in coordination of care for the patients. The learner is expected to be able to describe what is required to be visualized in each portion of the anatomic examination and describe how they are determining the technical adequacy of the image. They are also expected to be able to succinctly summarize and report the results of these examinations both in the absence and presence of anomalies. Evaluation of both the learner and this phase of the curriculum are achieved via online evaluation forms. Phases II and III are summarized in - Table 2.

Table 2 Phase II and III

\begin{tabular}{|c|c|}
\hline \multicolumn{2}{|c|}{$\begin{array}{l}\text { Phase II: } 8 \text { wks } \\
\text { Fellow interprets with MFM attending physician under supervision }\end{array}$} \\
\hline $\begin{array}{l}\text { Creation of ultrasound exam } \\
\text { report }\end{array}$ & $\begin{array}{l}\text { - Train on the reporting software and demonstrate knowledge necessary to complete an } \\
\text { - Discuss patient exam findings and evaluate images with RDMS } \\
\text { - Perform a brief real-time re-evaluation } \\
\text { - Communicate findings with the patient } \\
\text { - Arrange for follow-up if indicated } \\
\text { - Generate a report }\end{array}$ \\
\hline $\begin{array}{l}\text { Communication with refer- } \\
\text { ring physician }\end{array}$ & $\begin{array}{l}\text { - Communicate findings and recommendations with the referring provider. (If normal } \\
\text { findings, this is done through the written reports; if abnormal, this is communicated } \\
\text { directly to the provider.) }\end{array}$ \\
\hline $\begin{array}{l}\text { Communication of abnor- } \\
\text { mal results to patients and } \\
\text { co-ordination of follow-up } \\
\text { care }\end{array}$ & $\begin{array}{l}\text { - Learn how to communicate abnormal findings to the patient or couple } \\
\text { - Co-ordinate with genetic counselor and perinatal nurse coordinator to arrange future } \\
\text { care (including subspecialty referrals and delivery and postpartum plan) }\end{array}$ \\
\hline $\begin{array}{l}\text { Solidification of ultrasound } \\
\text { skills }\end{array}$ & $\begin{array}{l}\text { - Perform real-time ultrasound evaluation with the guidance of the ultrasound educator } \\
\text { - Participate in advanced fetal echocardiogram and fetal neurosonogram evaluation }\end{array}$ \\
\hline \multicolumn{2}{|c|}{$\begin{array}{l}\text { Phase III: } 8 \text { wks } \\
\text { Fellow learns to function as an independent MFM attending in the presence of an attending setting }\end{array}$} \\
\hline $\begin{array}{l}\text { Demonstration of indepen- } \\
\text { dent practice }\end{array}$ & - Manage the flow of the ultrasound unit under the guidance of the attending MFM \\
\hline Teaching and self-education & $\begin{array}{l}\text { - Participate in evidence-based practice. } \\
\text { - Present abnormal cases in the monthly multidisciplinary care conference on fetal } \\
\text { anomalies attended by neonatology, maternal-fetal medicine, and (as applicable) fetal } \\
\text { cardiology, neurology, surgery, urology, and other subspecialties. } \\
\text { - Participation in updating unit guidelines in accordance with emerging literature }\end{array}$ \\
\hline $\begin{array}{l}\text { Demonstrate incorporation } \\
\text { of research into practice }\end{array}$ & base related research \\
\hline
\end{tabular}

Abbreviations: MFM, maternal-fetal medicine; RDMS, registered diagnostic medical sonographer. 


\section{Phase III}

Fellows rotate through this phase in their last year of training as their final rotation prior to graduation. At the end of this phase, the fellow has mastered all of the skills necessary to be an independent perinatal sonologist who can participate in an MFM practice. The fellow at this stage functions as an independent consultant-in-training and is expected to run the unit in the presence of and under the supervision of the MFM attending physician. During this phase, the fellows are expected to review and interpret all images and see all the new patients. They are expected to perform brief confirmatory scanning on all basic or detailed fetal anatomic examination cases, confirm abnormal findings by obtaining standardized views, as well as counsel and coordinate patient care with their referring physician. The organization and design of our unit and our patient schedule template allows fellows to manage the usual volume of cases efficiently with the attending physician stepping in as needed. During this phase, time is also spent to develop and revise evidence-based ultrasound guidelines for the unit. The last 8 weeks are an opportunity to address all remaining areas of development in a fellow's training, and the fellow completes the training with the advanced knowledge and skills to practice independently. Additional mentored training and remediation according to the monitored objectives can be developed using the adult learning principles applied in this paper. Evaluation of both the learner and this phase of the curriculum are achieved via online evaluation forms.

\section{Invasive Procedures}

Invasive procedure training is a specialized area and demands specific attention. A full description of our amniocentesis training and the simulation models for amniocentesis and chorionic villus sampling developed at our center are available elsewhere. ${ }^{12,14}$

\section{Curriculum Evaluation}

We performed a posttraining survey of fellows who had graduated to assess their comfort with performing ultrasound, interpreting images, counseling patients, and running an ultrasound unit. This survey comprised of six Likert's scale questions and three open-end questions. The Likert's scale questions are shown (with responses) in - Table 3. The openend questions included: "What did you think was the most helpful part of the ultrasound training you received during your fellowship; Was there anything you would recommend to improve upon the ultrasound training you received during your fellowship; Do you have any additional comments or feedback regarding your ultrasound training." The survey was completed anonymously online via Qualtrics (Qualtrics Online Survey Software, Provo, UT); links to this survey were distributed by email. The last fellow included in this analysis graduated in July 2016 and completed the posttraining survey in October 2016. The number of sonograms performed or interpreted by each fellow was obtained by querying our sonogram interpretation software (Viewpoint 6, GE Healthcare, Waukesha, WI).

\section{Results}

To date, all fellows have been able to progress through the three phases of ultrasound training at the pace outlined above. All fellows that have graduated from this fellowship program have also satisfactorily met the ultrasound competencies required.

Data from posttraining Likert's scale surveys were available for nine of the nine (100\%) fellows who have graduated from this program. Time since graduation ranged from 0 to 9 years at the time of completion of the survey. One fellow completed their training prior to the creation of this ultrasound curriculum and eight fellows completed their training after the creation of this curriculum. Results are shown in -Table 3. Statistical analysis cannot be performed due to the low number of queried fellows but all fellows agreed or strongly agreed that they were comfortable with the listed items with the exception of one fellow who was neutral about comfort managing the unity flow. Comments were sought including what prior fellows would recommend to improve upon the ultrasound training. An early fellow commented that the recommended change had already been implemented: "more time scanning." One of the more recent

Table 3 Responses to posttraining survey regarding ultrasound training during fellowship ${ }^{a b}$

\begin{tabular}{|l|l|l|}
\hline $\begin{array}{l}\text { Prompt: when I initially finished my fellowship training in ultrasound, I felt } \\
\text { comfortable: }\end{array}$ & $\begin{array}{l}\text { Precurriculum } \\
\mathbf{n}=\mathbf{1}\end{array}$ & $\begin{array}{l}\text { Postcurriculum } \\
\boldsymbol{n}=\mathbf{8}\end{array}$ \\
\hline $\begin{array}{l}\text { Obtaining technically adequate images to complete a comprehensive anatomic survey } \\
\text { and Doppler's studies. }\end{array}$ & $5^{\mathrm{c}}$ & $5(4-5)$ \\
\hline Interpreting a comprehensive anatomic survey and Doppler's studies. & 5 & $5(4-5)$ \\
\hline $\begin{array}{l}\text { Interpreting and counseling about common anomalies (e.g.,: gastroschisis, echogenic } \\
\text { bowel, or soft markers of aneuploidy, etc.) }\end{array}$ & 5 & $5(4-5)$ \\
\hline $\begin{array}{l}\text { Interpreting and counseling about less common anomalies (e.g.,: skeletal dysplasia, } \\
\text { complex genetic syndromes.) }\end{array}$ & 5 & $4(4-5)$ \\
\hline Reading and interpreting ultrasounds on my own. & 5 & $5(4-5)$ \\
\hline Managing the work flow through the diagnostic unit. & 5 & $5(3-5)$ \\
\hline
\end{tabular}

aAll questions were administered via online survey as Likert items with 1 signifying "totally disagree" and 5 signifying "totally agree."

bThis survey comprised of these six Likert scale questions and three open-ended questions (responses in text).

'Values shown represent the median with ranges shown in parentheses. 


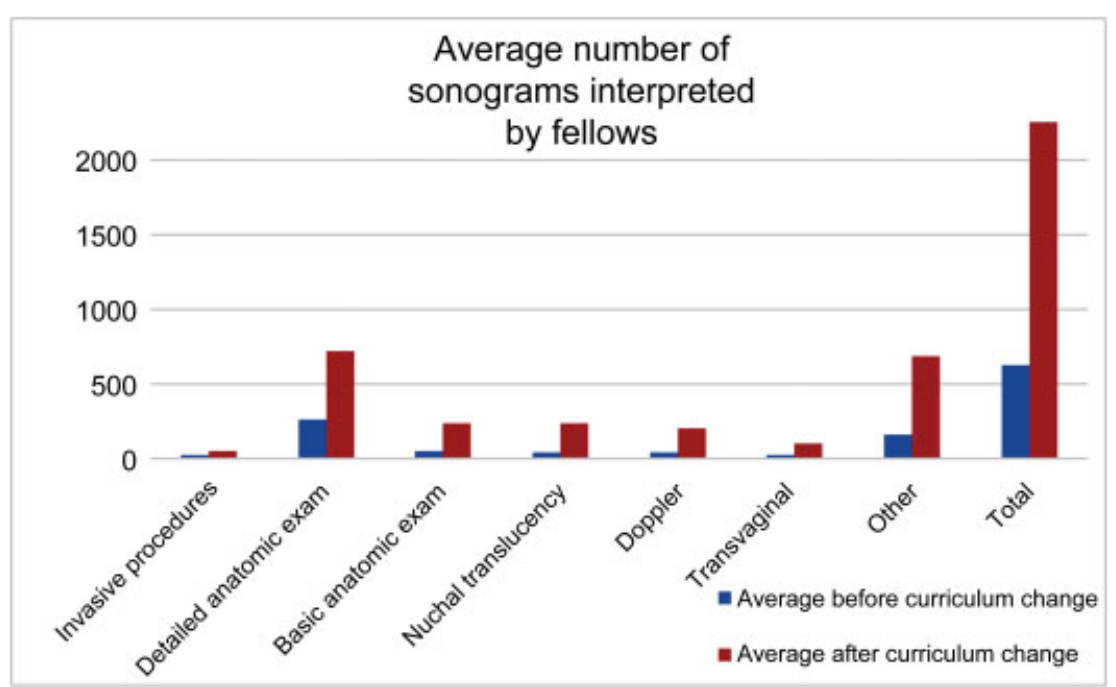

Fig. 2 Average number of sonograms interpreted by fellows. Following the implementation of this curriculum, the average number of sonograms interpreted increased.

fellows commented that "I really believe it (ultrasound training) was excellent. Barb Trampe is notably a unique asset to the fellowship program as I doubt very many other fellowship programs have invested in a dedicated sonographer to guide fellows through obtaining solid technical expertise with prenatal ultrasound."

Finally, implementation of this program did not adversely affect the number of sonograms that each fellow interpreted. Prior to this curriculum change, the fellow interpreted 628 total sonograms. Following this change, the average total number of sonograms interpreted was 2,257.5 per fellow $(n=8)$. The type of sonograms interpreted is shown in $\mathbf{- F i g .} \mathbf{2}$.

\section{Conclusion}

Our highly-structured training process provides a sound foundation in prenatal diagnosis that is grounded in the stepwise acquisition of measurable skills or competencies. At the end of the first 8-week training block, the fellow is able to perform standardized basic and detailed fetal anatomic examinations that meet AIUM guidelines. ${ }^{9}$ Because the curriculum is structured, faculty members are oriented to the expectations, and can easily adjust their teaching to the appropriate level for each fellow.

While the pace of training requires that fellows ascend a steep learning curve, all fellows to date have been able to complete this training according to the aforementioned schedule. If a fellow were unable to achieve competency in obtaining images during phase I of this curriculum, these competencies would be added to the start of phase II in an individualized manner to ensure that the competencies can be completed within a timely period without decreasing valuable sonologist experiences. Our success is likely a result of our investment in protecting the educational time allotted to the RDMS educator. This is achieved via supplemental funding from the department's education fund. Many training programs have a senior sonographer who serves as an educator but many programs don't sufficiently protect the educator's academic time. As a result, when the unit becomes busy, or when the senior sonographer has other administrative duties, learning suffers. Here, we describe how supporting this academic role accelerates learning from a variable baseline to proficiency and comfort within 8 weeks. Notably, all fellows in this program agreed (or totally agreed) that they felt comfortable meeting all the listed criteria in -Table 3.

Limitations to apply, this curriculum more universally include challenges in protecting the senior RDMS educator's time as this can be financially burdensome. Limitations to our evaluation of the program include the low number of fellows prior to the implementation of the program and the low overall number of fellows completing our program annually which limits our ability to assess the program.

In this era of physician accountability, following a competency-based curriculum anchored to specific objectives provides basis for feedback and for credentialing trainees. As our fellows progress through the curriculum, they receive meaningful formative feedback that is actionable in regard to remediation and advancement. At the end of the program, each fellow has an electronically documented portfolio of examinations that they have interpreted, as well as a patient list of examinations and procedures performed. Since the stepwise acquisition of skills necessary to perform these tasks is documented, it allows the program director to provide recommendations with confidence for the graduating fellows' privilege requests supporting their independent practice.

While general ultrasound curriculums to train skills and assess competency have been described for medical students, ${ }^{15,16}$ rheumatology fellows, ${ }^{17}$ and cardiology fellows, ${ }^{18}$ and obstetric ultrasound curriculums have been described for the education of medical students, ${ }^{15,19}$ radiology residents and fellows, ${ }^{20}$ and even obstetrics and gynecology residents, ${ }^{19,21}$ fellows, ${ }^{19}$ and midwives ${ }^{21}$ recent descriptions 
of a curriculum to achieve the goals of prenatal diagnostic competence that align with the ACGME milestones are lacking. ${ }^{5}$ Here, we describe a structured training process with weekly goals and a checklist of required images to ensure competency. In essence, this process applies one of the basic tenets of education that of scaffolding. As each component skill is learned, the fellow has a chance to reflect upon their performance and refine his/her approach. Each component skill is then combined into more complex "higher skills" and, by appropriate refinement, the fellow is able to meet more complex task requirements. ${ }^{22}$ The key element in this process is having an expert mentor involved in every step of the process. For scaffolding to enable, "... a novice to solve a problem, carry out a task or achieve a goal which would be beyond his unassisted effort ... (an expert) who is controlling those elements of the task that are initially beyond the learner's capacity ..." is required. ${ }^{23} \mathrm{~A}$ benefit of this process is that while the fellow is acquiring new skills, they are also refining their own learning process which can be applied toward life-long skill acquisition. ${ }^{7}$

Previously, Calhoun and Hume ${ }^{2}$ reported on their ultrasound training program for resident and fellows. Unlike their program where the focus is on the acquisition of knowledge base and mastery is demonstrated at the end, our paper describes a process for skill acquisition that allows for continuous formative feedback and individualized education plans by developing milestones and tracking individual progress. Since the desired outcome is independent practice, having a dedicated RDMS educator allows for the final assessment of our program to be the completion of real time image acquisition. In this era of competency based education, there is in addition to curricular theoretical training, a greater value to have a process that reinforces applicable subject and skill mastery. The next step in refining our program is to apply the Dreyfus model of skills acquisition $^{24}$ to develop assessable anchors for each objectified skill. Once a learning outcome has been broken down into discrete steps with anchors developed to document mastery, the steps can be modified and potentially applied to a variety of learners.

Our program, by following the explicit guidelines and expectations set out by the AIUM and ACGME for practicing MFM fellowship graduates, provides a degree of national standardization applicable to evaluation and credentialing of new practitioners. ${ }^{5,9}$ Following this program would allow for the stepwise documentation of skills assessment necessary for an MFM fellow to progress under the tutelage of an expert and develop into an independent practitioner. The competency-based curriculum and development of milestones may improve standardization and accountability for fellowship training. ${ }^{25}$ Our model is adaptable to a spectrum of learners in the ultrasound unit and is adaptable to a variety of clinic settings.

\section{Previous Presentation}

This curriculum was previously presented in poster format at the 34th annual meeting of the Society for Maternal-Fetal Medicine, New Orleans, LA, Feb 3-8, 2014.

\section{Conflict of Interest}

The authors report no relevant financial disclosures.

\section{Acknowledgments}

We would like to thank Robert Koehler, medical librarian at UnityPoint-Meriter Hospital, for his generous assistance. We would also like to thank Erika Nightingale, RDMS and Baby Boy Nightingale for their assistance with -Fig. 1. We would also like to thank Heather Schierloh, MS, RDMS, RVT, RT(R), for her assistance with the figures.

\section{References}

1 Wax J, Minkoff H, Johnson A, et al. Consensus report on the detailed fetal anatomic ultrasound examination: indications, components, and qualifications. J Ultrasound Med 2014;33(02): 189-195

2 Calhoun BC, Hume RF. Integrated Obstetric Curriculum for Obstetrics and Gynecology Residency, Radiology Residency and Maternal-Fetal Medicine Fellowship program at an accredited American Institute of Ultrasound in Medicine Diagnostic Ultrasound Center. Ultrasound Obstet Gynecol 2000;16(01): 68-71

3 Lee W, Hodges AN, Williams S, Vettraino IM, McNie B. Fetal ultrasound training for obstetrics and gynecology residents. Obstet Gynecol 2004;103(02):333-338

4 Wiggins G, McTighe J. Understanding by Design. 2nd ed. Alexandria, VA: Association for Supervision and Curriculum Development; 2005

5 Accreditation Council for Graduate Medical Education, The American Board of Obstetrics and Gynecology, The American College of Obstetricians and Gynecologists. The maternal-fetal medicine milestones project. 2016; available from: http://www.acgme. org/Portals/0/PDFs/Milestones/MaternalFetalMedicineMilestones. pdf. Accessed on September 27, 2018

6 Suneja A, Suneja C. The Lean Doctors Workbook: An Application Guide for Transforming Outpatient Clinic Systems with Lean. Milwaukee, WI: American Society for Quality, Quality Press; 2011

7 Knowles MS, Holton EF, Holton Ed, Swanson RA. The Adult Learner: The Definitive Classic in Adult Education and Human Resource Development. 6th ed. Burlington, MD: Elsevier; 2005

8 Gilstrap LC. American Board of Obstetrics and Gynecology. General requirements for gynecologic oncology, maternal-fetal medicine, and reproductive endocrinology and infertility and special requirements for maternal-fetal medicined [Internet]. Vol. September, ABOG program requirements for fellowship graudate medical education. 2014. Available from: https://www.abog. org/docs/default-source/default-document-library/guide-tolearning-mfm-2018.pdf. Accessed October 18, 2018

9 American Institute of Ultrasound in Medicine. AIUM practice guideline for the performance of obstetric ultrasound examinations. J Ultrasound Med 2013;32(06):1083-1101

10 International Society of Ultrasound in Obstetrics and Gynecology. ISUOG Education Committee recommendations for basic training in obstetric and gynecological ultrasound. Ultrasound Obstet Gynecol 2014;43(01):113-116

11 Perinatal Quality Foundation. Cervical length education and review. Available from: https://clear.perinatalquality.org/2016; accessed on September 27, 2018

12 Khurshid N, Trampe B, Heiser T, et al. Abstract 420: Impact of an amniocentesis simulation curriculum for training in MFM fellowship program. Am J Obstet Gynecol 2014;210(1, Supplement): S212-S213

13 Iruretagoyena JI, Shah D, Malinger G. Dedicated fetal neurosonographic evaluation improves patient care and maternal fetal 
medicine fellow training. J Matern Fetal Neonatal Med 2016;29 (03):482-486

14 Iruretagoyena JI, Trampe B, Stewart K, Droste S. A transcervical chorionic villus sampling model for teaching. J Ultrasound Med 2013;32(08):1489-1492

15 Bahner DP, Royall NA. Advanced ultrasound training for fourthyear medical students: a novel training program at The Ohio State University College of Medicine. Acad Med 2013;88(02):206-213

16 Bahner DP, Adkins EJ, Hughes D, Barrie M, Boulger CT, Royall NA. Integrated medical school ultrasound: development of an ultrasound vertical curriculum. Crit Ultrasound J 2013;5(01):6-15

17 Kissin EY, Niu J, Balint P, et al. Musculoskeletal ultrasound training and competency assessment program for rheumatology fellows. J Ultrasound Med 2013;32(10):1735-1743

18 Srivastava S, Printz BF, Geva T, et al; Society of Pediatric Cardiology Training Program Directors; American College of Cardiology; American Academy of Pediatrics; American Heart Association. Task force 2: pediatric cardiology fellowship training in noninvasive cardiac imaging. SPCTPD/ACC/AAP/AHA. Circulation 2015; 132(06):e57-e67

19 Tsai PJ, Wong S, Zalud I. Ultrasound education in obstetrics and gynecology: Hawai'i experience. Hawaii J Med Public Health 2013;72(05):172-174

20 Kasales CJ, Coulson CC, Mauger D, Chertoff JD, Matthews A. Training in obstetric sonography for radiology residents and fellows in the United States. AJR Am J Roentgenol 2001;177(04):763-767

21 Shaw-Battista J, Young-Lin N, Bearman S, Dau K, Vargas J. Interprofessional obstetric ultrasound education: successful development of online learning modules; case-based seminars; and skills labs for registered and advanced practice nurses, midwives, physicians, and trainees. J Midwifery Womens Health 2015;60(06):727-734

22 Bruner JS. Organization of early skilled action. Child Dev 1973;44 (01):1-11

23 Wood D, Bruner JS, Ross G. The role of tutoring in problem solving. . J Child Psychol Psychiatry 1976;17(02):89-100

24 Benner P. Using the dreyfus model of skill acquisition to describe the interpret skill acquisition and clinical judgment in nursing practice and education. Bull Sci Technol Soc 2004;24(03):188-199

25 Green ML, Aagaard EM, Caverzagie KJ, et al. Charting the road to competence: developmental milestones for internal medicine residency training. J Grad Med Educ 2009;1(01):5-20
26 Committee on Obstetric Practice, the American Institute of Ultrasound in Medicine, and the Society for Maternal-Fetal Medicine. Committee opinion no 700: methods for estimating the due date. Obstet Gynecol 2017;129(05):e150-e154

27 Reddy UM, Abuhamad AZ, Levine D, Saade GR; Fetal Imaging Workshop Invited Participants. Fetal imaging: executive summary of a joint Eunice Kennedy Shriver National Institute of Child Health and Human Development, Society for Maternal-Fetal Medicine, American Institute of Ultrasound in Medicine, American College of Obstetricians and Gynecologists, American College of Radiology, Society for Pediatric Radiology, and Society of Radiologists in Ultrasound Fetal Imaging workshop. Obstet Gynecol 2014;123(05):1070-1082

28 The Association for Medical Ultrasound: American Institute of Ultrasound in Medicine. AIUM practice parameter for documentation of an ultrasound examination. 2015; cited January 1, 2017 Available from: http://www.aium.org/resources/guidelines/documentation.pdf; accessed on September 27, 2018

29 Winter TC, Kennedy AM, Byrne J, Woodward PJ. The cavum septi pellucidi: why is it important? J Ultrasound Med 2010;29(03): 427-444

30 Callen PW, Callen AL, Glenn OA, Toi A. Columns of the fornix, not to be mistaken for the cavum septi pellucidi on prenatal sonography. J Ultrasound Med 2008;27(01):25-31

31 Viñals F, Heredia F, Giuliano A. The role of the three vessels and trachea view (3VT) in the diagnosis of congenital heart defects. Ultrasound Obstet Gynecol 2003;22(04):358-367

32 The Association for Medical Ultrasound: American Institute of Ultrasound in Medicine. Practice Parameter for the Performance of Fetal Echocardiography 2013; available from: http://www. aium.org/resources/guidelines/fetalecho.pdf; accessed on September 27, 2018

33 Nelson TR, Fowlkes JB, Abramowicz JS, Church CC. Ultrasound biosafety considerations for the practicing sonographer and sonologist. J Ultrasound Med 2009;28(02):139-150

34 Bergland C. Curiosity and conscientiousness more Important than Intelligence: how to beat the "been-there-done-that" doldrums Psychology Today. 2011; cited April 24, 2017; available from: https://www.psychologytoday.com/blog/the-athletes-way/ 201112/curiosity-and-conscientiousness-more-important-intelligence; accessed on September 27, 2018 